\title{
AVALIAÇÃO DO IMPACTO DA AGRICULTURA EM ÁREAS DE PROTEÇÃO AMBIENTAL, PERTENCENTES À BACIA HIDROGRÁFICA DO RIO RIBEIRA DE IGUAPE, SÃO PAULO
}

\author{
Maria Nogueira Marques*, Marycel Barbosa Cotrim e Maria Aparecida Faustino Pires
}

Centro de Química e Meio Ambiente, Instituto de Pesquisas Energéticas e Nucleares, Av. Prof. Lineu Prestes, 2242,

05508-000 São Paulo - SP, Brasil

Osvaldo Beltrame Filho

Unidade de Negócios do Vale do Ribeira, Companhia de Saneamento Básico do Estado de São Paulo, Registro - SP, Brasil

Recebido em 30/6/06; aceito em 18/1/07; publicado na web em 24/7/07

\begin{abstract}
ASSESSMENT OF THE IMPACT OF AGRICULTURE ON ENVIRONMENTAL PRESERVATION AREAS OF THE RIBEIRA DE IGUAPE RIVER, SÃO PAULO. In order to ascertain the impact of agricultural activities on water quality of the Ribeira de Iguape River Basin in the state of São Paulo, surface water areas for catchment and drinking water have been characterized. The sampling period covered March/2002 - February/2003 and January/2004 at 10 different catchment points. SPE-LC-UV/Vis was used to monitor various pesticide classes such as carbamates, triazines and nitroanilines. The results revealed that water quality is associated with seasonal variation. Of 152 samples analyzed, only $24 \%$ showed the presence of pesticides, particulary during the wet season. High variability in $\mathrm{pH}$, turbidity and color were observed.
\end{abstract}

Keywords: Ribeira de Iguape River Basin; water quality; pesticides.

\section{INTRODUÇÃO}

A humanidade, até algumas décadas atrás, tinha a água como um bem infinito e que a capacidade de autodepuração dos corpos d'água também o era. Mas nas últimas décadas, o rápido desenvolvimento industrial, o aumento do número de habitantes e da produtividade agrícola trouxeram como conseqüência a preocupação com a qualidade e disponibilidade da água para consumo humano, devido à rápida degradação dos corpos d‘água.

Estes fatos mostraram a fragilidade da capacidade autodepurativa do ciclo aquático mediante a grande demanda exigida pelos sistemas socioeconômicos da sociedade atual, mostrando-nos que os recursos hídricos são um bem finito e, portanto, exigem uma atenção especial na gestão de seu uso, além da necessidade eminente de se promover o saneamento dos esgotos urbanos e um controle rigoroso nos rejeitos industriais descartados nos corpos d'água.

A constante utilização dos recursos hídricos e a introdução de substâncias tóxicas nos ecossistemas aquáticos têm requerido um maior número de estudos para avaliar e manter a sua qualidade.

A qualidade da água pode ser definida como sendo um conjunto das características físicas, químicas e biológicas de um certo corpo d'água, cujos critérios de avaliação da qualidade dependem do propósito do uso ${ }^{1}$.

Um dos grandes desafios para um programa de monitoramento da qualidade da água na bacia é conhecer o funcionamento do ecossistema, organizar um banco de dados sobre a qualidade da água e entender os fatores que afetam a qualidade regional e nacionalmente ${ }^{2}$.

Dentre os principais parâmetros indicadores da qualidade da água potável, tem-se a cor, a turbidez e o $\mathrm{pH}$.

A cor, utilizada como indicador físico para padrão de potabilidade, embora seja um atributo mais estético da água, é uma característica derivada da existência de substâncias em solução, sendo essas, na grande maioria dos casos, de natureza orgânica. A presença de cor provoca repulsa psicológica no consumidor. No

*e-mail: mmarques@ipen.br controle da qualidade das águas nas estações de tratamento, a cor é um parâmetro fundamental, não só por se tratar de padrão de potabilidade, como também por ser parâmetro operacional de controle da qualidade da água bruta, da água decantada e da água filtrada, servindo como base para a determinação das dosagens de produtos químicos a serem adicionados, dos graus de mistura, dos tempos de contato e de sedimentação das partículas floculadas.

A Resolução $n^{\circ}$ 357/05 do Conselho Nacional de Meio Ambiente - CONAMA ${ }^{3}$, que dispõe sobre os níveis de qualidade das águas naturais do território brasileiro, inclui a cor como parâmetro de classificação. Esta limitação é importante, pois nas águas naturais associa-se a problemas de estética, às dificuldades na penetração da luz e à presença de compostos recalcitrantes (não biodegradáveis, isto é, de taxas de decomposição muito baixas) que, em geral, são tóxicos aos organismos aquáticos ${ }^{4}$.

A turbidez também é um parâmetro que indica a qualidade estética das águas para abastecimento público. Nas estações de tratamento de água, a turbidez é um parâmetro operacional de extrema importância para o controle dos processos de coagulação, floculação, sedimentação e filtração. Há uma preocupação adicional que se refere à presença de turbidez nas águas submetidas à desinfecção pelo cloro. Estas partículas grandes podem abrigar microrganismos, protegendo-os contra a ação deste agente desinfetante.

Nas águas naturais, a presença da turbidez provoca a redução de intensidade dos raios luminosos que penetram no corpo d'água, influindo decisivamente nas características do ecossistema presente. Quando sedimentadas, estas partículas formam bancos de lodo onde a digestão anaeróbia leva à formação de gases metano e carbônico, principalmente, além de nitrogênio gasoso e do gás sulfídrico, que é malcheiroso.

A influência do $\mathrm{pH}$ sobre os ecossistemas aquáticos naturais dáse diretamente, devido a seus efeitos sobre a fisiologia das diversas espécies. Também o efeito indireto é muito importante, podendo determinadas condições de $\mathrm{pH}$ contribuir para a precipitação de elementos químicos tóxicos como metais pesados; outras condições podem exercer efeitos sobre as solubilidades de nutrientes ${ }^{4}$. 
Por influir em diversos equilíbrios químicos que ocorrem naturalmente ou em processos unitários de tratamento de águas, o $\mathrm{pH}$ é um parâmetro importante em muitos estudos no campo do saneamento ambiental.

Nas estações de tratamento de águas, são várias as unidades cujo controle envolve as determinações de $\mathrm{pH}$ : a coagulação e a floculação que a água sofre inicialmente é um processo unitário dependente do $\mathrm{pH}$; a desinfecção pelo cloro é outro processo dependente do $\mathrm{pH}$; a própria distribuição da água final é afetada pelo $\mathrm{pH}$. Outros processos físico-químicos de tratamento também são dependentes do $\mathrm{pH}^{4}$.

A agricultura, um dos principais componentes da economia mundial, contribui de forma cada vez mais acentuada para a degradação da qualidade da água através do lançamento, mesmo que indireto, de poluentes na água, como agrotóxicos, sedimentos, fertilizantes, adubo animal e outras fontes de matéria orgânica e inorgânica. Muitos destes poluentes atingem as fontes de água superficial e subterrânea durante o processo de escoamento e percolação, chamadas de fontes não-pontuais de poluição ${ }^{5}$. As principais implicações da degradação da qualidade da água são descontrole do ecossistema, perda na biodiversidade, contaminação de ecossistemas marinhos, contaminação das fontes de águas subterrâneas e mortes provocadas por doenças transmitidas pelo não tratamento da água ${ }^{6}$.

Os agrotóxicos estão entre os principais instrumentos do atual modelo de desenvolvimento da agricultura brasileira, mas devido aos efeitos adversos que podem causar à exposição humana e ao meio ambiente, a preocupação com esses produtos cresce em importância com o aumento das vendas.

O relatório realizado pelo Instituto Brasileiro do Meio Ambiente e dos Recursos Naturais Renováveis - IBAMA (2000) de consumo de ingredientes ativos de agrotóxicos e afins contempla 284 ingredientes ativos, com um consumo nacional de agrotóxicos de 131.970 t. Na lista dos 10 agrotóxicos de maior consumo no país 5 são herbicidas, onde estão inclusos a atrazina e a trifluralina ${ }^{7}$.

Os agrotóxicos, devido às suas propriedades, foram e são largamente utilizados e o seu uso tem contribuído muito para o aumento do rendimento agrícola e a maior abundância de alimentos. Contudo, pouca atenção foi dada por ocasião do seu aparecimento, principalmente quanto ao aspecto toxicológico e às implicações do seu uso. De acordo com Hayes e Laws ${ }^{8}$ as principais vias de contaminação ambiental por agrotóxicos são aplicação direta na água; lixiviação do solo de áreas contaminadas; contaminação de águas subterrâneas por percolação do solo; liberação de efluentes industriais; usos domésticos e despejos de materiais de descarte.

$\mathrm{Na}$ literatura internacional são inúmeros os trabalhos associados a esse tema, abordando também novas metodologias de determinação dos agrotóxicos. Na sua maioria, estes métodos associam a extração em fase sólida (SPE) à cromatografia gasosa ou líquida9-21.

A maioria dos estudos de monitoramento e pesquisas realizados em bacias ou microbacias hidrográficas e fontes destinadas ao abastecimento público no Brasil avaliam as mudanças, espacial e temporal, na qualidade da água do rio ou bacia em relação aos parâmetros físico-químicos, nutrientes, alcalinidade, contribuintes inorgânicos e avaliação microbiológica. Os estudos são muito escassos em relação aos agrotóxicos ${ }^{22-28}$.

Dessa forma, a principal atividade deste trabalho foi avaliar a influência do uso de agrotóxicos da agricultura local na qualidade da água em áreas de captação de água na Bacia Hidrográfica do Rio Ribeira de Iguape. A literatura consultada mostrou que não existe histórico do monitoramento de agrotóxicos nessa bacia. Amostras de água bruta e tratada foram coletadas, durante um período anual, com coletas bimestrais, abordando principalmente dois períodos distintos, o período seco e o chuvoso, em 18 estações de tratamento de água (ETA) da Companhia de Saneamento Básico do Estado de São Paulo, SABESP, pertencentes à bacia hidrográfica. Após avaliação preliminar, o estudo foi direcionado para 10 estações de tratamento e seus respectivos pontos de captação na bacia.

Foram avaliados neste trabalho os compostos: aldicarbe, carbofurano e carbaril, do grupo dos carbamatos; a simazina e atrazina, do grupo das triazinas e a trifluralina, do grupo das nitroanilinas.

Vários fatores foram observados para a escolha desses agrotóxicos: sua utilização, tanto em escala mundial, nacional e regional; freqüência nos estudos de monitoramento internacionais, tanto em água bruta como tratada; ausência de informação e de dados de monitoramento em escala nacional e regional e persistência e características físico-químicas ${ }^{10,12,15,19,20,24,26,27,29-33}$.

Vale salientar que o carbofurano e o carbaril estão entre os agrotóxicos mais empregados na área de estudo e que a simazina, a atrazina e a trifluralina estão entre os agrotóxicos inclusos como parâmetro de controle de potabilidade.

\section{Características gerais da Bacia hidrográfica do Ribeira de Iguape}

A Bacia hidrográfica do Ribeira de Iguape, demoninada também de Vale do Ribeira e Unidade de Gerenciamento de Recursos Hídricos 11, Vale do Ribeira e Litoral Sul (UGRHI - 11), está localizada na região sul do estado de São Paulo e leste do estado do Paraná, entre as latitudes $23^{\circ} 50^{\prime}$ e $25^{\circ} 30^{\prime}$ ao Sul do Equador e longitudes $46^{\circ} 50^{\prime}$ e $50^{\circ} 00^{\prime}$ ao Oeste de Greenwich. Abrange uma área de aproximadamente $25.000 \mathrm{~km}^{2}$, dos quais cerca de $17.000 \mathrm{~km}^{2}$ (dois terços) estão no território paulista ${ }^{34}$. No critério de escolha da área piloto foram observados locais com pouca ou nenhuma atividade antrópica com área de proteção ambiental e estação ecológica.

Com uma área de drenagem de $16.607 \mathrm{~km}^{2}$, abrange 23 municípios, com uma população total de 358.565 habitantes, sendo 234.124 na zona urbana. As maiores cidades são Registro, Cajatí, Iguape e Apiaí ${ }^{34,35}$. Esta Bacia compõe a região dos estados de São Paulo e Paraná mais privilegiada pelas belezas que a natureza pode oferecer. A área de floresta natural do estado de São Paulo também está concentrada na região. Nesta encontram-se a Área de Proteção Ambiental da Serra do Mar, os Parques Estaduais do Alto Ribeira e Jacupiranga, as Áreas de Proteção Ambiental de Cananéia-IguapePeruíbe e da Ilha Comprida e a Estação Ecológica da Juréia.

A UGRHI 11 - Ribeira de Iguape e Litoral Sul apresenta características muito singulares, como os mais baixos índices de desenvolvimento do estado, uma economia baseada principalmente na agricultura (banana, chá e arroz), mineração e extrativismo vegetal (palmito). Os parâmetros socioeconômicos e demográficos apresentam uma imagem contrastante com o resto do estado. Além disso, é uma região peculiar por ser uma das áreas menos urbanizadas do estado.

O rio Ribeira nasce no Paraná e somente passa a ser denominado Ribeira de Iguape após a confluência com seu principal afluente, o Juquiá. Segundo os parâmetros do Conselho Nacional do Meio Ambiente - CONAMA no $357 / 05^{3}$, todos os corpos d'água dessa região foram enquadrados na Classe 2 (águas que podem ser destinadas ao abastecimento humano, após tratamento convencional). Com exceção dos rios Sete Barras, Turvo e seus afluentes, São João, Córrego dos Veados, Córrego Poço Grande, Rio João Surrá e seus afluentes que pertencem à Classe 1 (águas que podem ser destinadas ao abastecimento para consumo humano, após tratamento simplificado) $)^{34,35}$ 
A Bacia do Ribeira de Iguape é a única no estado de São Paulo onde a relação disponibilidade versus demanda é extremamente positiva. Com uma situação privilegiada em relação às demais no tocante à qualidade e quantidade de água, tanto por apresentar a mais elevada disponibilidade como pela demanda ainda pequena dos recursos hídricos superficiais e subterrâneos ${ }^{36}$. Portanto, é importante que se faça um planejamento avaliando-se a demanda atual e o potencial da bacia e ainda se analisem as perspectivas de evolução, procurando compatibilizar o desenvolvimento regional com a proteção dos recursos hídricos, escolhendo diretrizes de desenvolvimento adequadas à implantação na região de atividades que sejam compatíveis com a estrutura do solo e a preservação da sua cobertura vegetal, na medida em que isto apresente maior ou menor importância. Segundo o Departamento de Águas e Energia Elétrica, DAEE ${ }^{36}$, a Bacia do Ribeira de Iguape tem uma demanda total de $6,08 \mathrm{~m}^{3} \mathrm{~s}^{-1}$ dividida em 1,$11 ; 2,67$ e $2,3 \mathrm{~m}^{3} \mathrm{~s}^{-1}$ para os usos: urbano, industrial e irrigação, respectivamente. A sua disponibilidade hídrica, na forma de $\mathrm{Q}_{7,10}$, atinge níveis de $179,24 \mathrm{~m}^{3} \mathrm{~s}^{-1}$, portanto, a relação demanda/ disponibilidade para toda a bacia é somente de 3,39\%.

O monitoramento neste trabalho foi realizado em amostras de água bruta (coletadas no ponto de captação para o tratamento de água) e tratada (destinada ao abastecimento público). Deve-se salientar que no Brasil a Portaria $n^{\circ} 518 / \mathrm{MS} / 04^{37}$ estabelece os padrões atuais de potabilidade de água para o abastecimento público e a Resolução CONAMA n ${ }^{\circ} 357 / 05^{3}$ trata os recursos hídricos por classe, diferenciando-as pelos padrões numéricos de emissão dos poluentes que podem ser lançados nos corpos d'água. Na seção I, o CONAMA classifica as águas doces em classes 1,2 e 3 para as águas destinadas ao abastecimento para consumo humano, com tratamento simplificado, convencional ou avançado, respectivamente.

Na Tabela 1 são apresentados os valores máximos permitidos pela Portaria $n^{\circ} 518 / \mathrm{MS} / 04^{37}$ e a especificação dos parâmetros por classe das águas segundo a Resolução CONAMA nº 357/05³ , para os parâmetros monitorados neste trabalho.

Tabela 1. Valores máximos permissíveis na Portaria no 518/MS/ $04^{37}$ e Resolução CONAMA n ${ }^{\circ} 357 / 05^{3}$ para os parâmetros monitorados

\begin{tabular}{lccccc}
\hline Parâmetros & Unidades & $\begin{array}{c}\text { Portaria } \mathrm{n}^{\circ} \\
518 / \mathrm{MS} / 04\end{array}$ & \multicolumn{2}{c}{ CONAMA $\mathrm{n}^{\circ}$} & $357 / 05$ \\
& & & Classe 1 & Classe 2 & Classe 3 \\
\hline Cor & $\mathrm{UH}$ & 15 & Natural & $\leq 75$ & $\leq 75$ \\
Turbidez & $\mathrm{UT}$ & 1 & $\leq 40$ & $\leq 100$ & $\leq 100$ \\
$\mathrm{pH}$ & - & $6,0-9,5$ & $6,0-9,0$ & $6,0-9,0$ & $6,0-9,0$ \\
Agrotóxicos & & & & & \\
Aldicarbe & $\mu \mathrm{g} \mathrm{L}^{-1}$ & - & - & - & - \\
Atrazina & $\mu \mathrm{g} \mathrm{L}^{-1}$ & 2,0 & 2,0 & 2,0 & 2,0 \\
Carbofurano & $\mu \mathrm{g} \mathrm{L}^{-1}$ & - & - & - & - \\
Carbaril & $\mu \mathrm{g} \mathrm{L}^{-1}$ & - & 0,02 & 0,02 & 70,0 \\
Simazina & $\mu \mathrm{g} \mathrm{L}^{-1}$ & 2,0 & 2,0 & 2,0 & - \\
Trifluralina & $\mu \mathrm{g} \mathrm{L}^{-1}$ & 20,0 & 0,2 & 0,2 & - \\
\hline & & & & &
\end{tabular}

\section{PARTE EXPERIMENTAL}

\section{Equipamento e materiais}

Usou-se cromatógrafo líquido de alta eficiência LC modelo LC - 10Ai da Shimadzu, programador de gradiente para dois solventes, um injetor Rheodyne 9725, com "loop" de $20 \mu \mathrm{L}$. Este sistema está acoplado a um detector UV/visível SPD 10Ai da Shimadzu e um microprocessador de dados equipado com o programa CLASSLC10/
M10 (Shimadzu); coluna de fase reversa Shim-Pach CCL-ODS $C_{18}$ (150 x 4,6 mm ID $5 \mu \mathrm{m})$ Shimadzu; pré-coluna G-ODS C $\mathrm{C}_{18}(10$ x 4,0 mm ID $5 \mu \mathrm{m})$ shimadzu; Sistema purificador de água Easypure RF (Barnestd); colunas de extração em fase sólida ("Solid Phase Extration”) - SPE ENVI C $18500 \mathrm{mg} 3 \mathrm{~mL}$ (polipropileno) Supelco; sistema de extração $\mathrm{SPE}$ a vácuo desenvolvido no laboratório ${ }^{31}$; sistema de filtração de soluções em membranas a vácuo (Santórios).

\section{Reagentes e soluções}

Todos os reagentes utilizados foram de grau analítico cromatográfico ou compatível, de procedência: EM Merck, Mallinckrodt Nanograde, Merck, J.T. Baker, Ciba-Geigy e Institut of Organic Industrial Chemistry.

Água ultrapura de baixa condutividade, inferior a $1 \mu \mathrm{S} \mathrm{cm}^{-1}$; acetonitrila; solução 50\% (v/v) acetonitrila e água; solução de ácido monocloroacético $2,5 \mathrm{~mol} \mathrm{~L}^{-1}$; solução de acetato de potássio 2,5 mol L ${ }^{-1}$; solução tampão ácido monocloroacético $\left(2,5 \mathrm{~mol} \mathrm{~L}^{-1}\right) /$ acetato de potássio $\left(2,5 \mathrm{~mol} \mathrm{~L}^{-1}\right) \mathrm{pH} 3(312 \mathrm{~mL} / 200 \mathrm{~mL} \mathrm{v} / \mathrm{v})$; tiossulfato de sódio; padrões de referência com certificados de purezas: aldicarbe $99 \%$, atrazina 99,8\%, carbaril 99,8\%, carbofurano $99,9 \%$, simazina $99,8 \%$ e trifluralina $99,5 \%$; solução padrão estoque (individual) à concentração de $10 \mathrm{mg} \mathrm{L}^{-1} \mathrm{em}$ acetonitrila; solução padrão intermediária contendo todos os compostos à concentração de $1,0 \mathrm{mg} \mathrm{L}^{-1} \mathrm{em}$ acetonitrila (ACN).

Observação: Todas as soluções padrão preparadas foram mantidas no congelador e na ausência de luz. Estas soluções, armazenadas adequadamente, são estáveis por 1 ano ${ }^{10,27,38}$.

\section{Determinação de carbamatos, triazinas e nitroanilinas utilizando LC - UV/visível}

A metodologia empregada neste trabalho foi desenvolvida por Lebre $^{38}$, no laboratório da Divisão de Diagnóstico Ambiental do Centro de Química e Meio Ambiente do IPEN/CNEN - SP. Neste trabalho, esta metodologia foi otimizada para a determinação dos herbicidas atrazina, simazina e trifluralina e dos inseticidas aldicarbe, carbofurano e carbaril em amostras de águas, utilizando a SPE para pré-concentração e extração dos compostos, em conjunto com a cromatografia líquida de alta eficiência (LC) com detecção UV/visível. Utilizou-se o sistema "off-line", onde a amostra é extraída separadamente e posteriormente uma alíquota do extrato é injetada no cromatógrafo, com o objetivo de avaliar o comprometimento da qualidade da água destinada à captação e distribuição de água potável.

\section{Extração de fase sólida}

As amostras foram submetidas à $\mathrm{SPE}$, em colunas de polipropileno de $3 \mathrm{~mL}$ (preenchidas com $500 \mathrm{mg}$ da fase $\mathrm{C}_{18}$ ), procedendo-se da seguinte forma: as colunas foram condicionadas com $30 \mathrm{~mL}$ de acetonitrila (ACN) e $3 \mathrm{~mL}$ de água ultra-pura, para ativação dos sítios e eliminação de impurezas; em seguida, $250 \mathrm{~mL}$ da amostra foram passadas através da coluna de SPE a um fluxo de 5,0 a $6,0 \mathrm{~mL} \mathrm{~min}^{-1}$, para extração dos analitos de interesse. Foram adicionados $3 \mathrm{~mL}$ de água ultra-pura para lavagem da coluna, antes da etapa de secagem sob vácuo. Os compostos foram eluídos da coluna adicionando-se 2 vezes o volume de $3 \mathrm{~mL}$ do solvente acetonitrila. Para análise no cromatógrafo líquido, o solvente foi evaporado até a secura em fluxo de nitrogênio, em seguida o resíduo foi diluído com $2 \mathrm{~mL}$ da solução $50 \%$ (v/v) acetonitrila e água e injetado um volume de $20 \mu \mathrm{L}$ no cromatógrafo líquido. Teve-se o cuidado de não deixar a coluna secar nas etapas de condicionamento, percolação da amostra e eliminação de interferentes. Ao 
adicionar-se o volume de solvente ou água nas etapas de extração, deixou-se este em contato por $2 \mathrm{~min}$.

\section{Condições de operação do LC - UV/visível}

Para a separação dos compostos no cromatógrafo líquido, utilizou-se uma coluna de fase reversa $\mathrm{C}_{18}$, Shim-Pack CCL-ODS e uma pré-coluna G-ODS, ambas da Shimadzu. A eluição foi realizada utilizando-se um gradiente da fase móvel aumentando a composição do solvente orgânico em função do tempo de análise, como apresentado na Tabela 2.

As condições de operação do sistema foram: fluxo da fase móvel: 1,0 $\mathrm{mL} \mathrm{min}{ }^{-1}$; pressão: $96 \mathrm{kgf} \mathrm{cm}^{-2}$; volume de injeção: 20 $\mu \mathrm{L}$; detecção no ultravioleta: $220 \mathrm{~nm}$.

Tabela 2. Programação do gradiente de eluição utilizando como fase móvel água (A) e acetonitrila (B)

\begin{tabular}{lccc}
\hline Tempo (min) & $\% \mathrm{~A}$ & $\% \mathrm{~B}$ & Curva \\
\hline 0 & 52 & 48 & - \\
4,5 & 52 & 48 & - \\
20,0 & 20 & 80 & Convexa* \\
21,0 & 20 & 80 & - \\
\hline
\end{tabular}

*Curva de gradiente não linear, convexa, inclinação de -8 .

\section{Linearidade e sensibilidade}

Construíram-se as curvas analíticas, para verificar a linearidade e sensibilidade da técnica LC-UV/visível para os compostos avaliados, analisando-se soluções padrão de diferentes concentrações 0,$02 ; 0,05 ; 0,08 ; 0,20$ e $0,50 \mathrm{mg} \mathrm{L}^{-1}$, contendo todos os pesticidas diluídos em solução com $50 \%$ (v/v) acetonitrila e água.

Determinaram-se o limite de detecção (LD) e quantificação (LQ) com a utilização da medida do sinal e do ruído, injetando-se soluções-padrão em triplicata.

Na Tabela 3 são apresentados a faixa de estudo da linearidade, o coeficiente de correlação (r), os limites de detecção e determinação.

Tabela 3. Parâmetros utilizados para os cálculos do LD e LQ

\begin{tabular}{lcccc}
\hline Composto & $\begin{array}{c}\text { Faixa de estudo da } \\
\left.\text { linearidade }(\mu \mathrm{g} \mathrm{L})^{-1}\right)\end{array}$ & $\mathrm{r}$ & $\begin{array}{c}\mathrm{LD} \pm \mathrm{dp}^{\mathrm{a}} \\
\left.(\mu \mathrm{g} \mathrm{L})^{-1}\right)\end{array}$ & $\begin{array}{c}\mathrm{LQ} \pm \mathrm{dp}^{\mathrm{a}} \\
\left(\mu \mathrm{g} \mathrm{L}^{-1}\right)\end{array}$ \\
\hline Aldicarbe & $20,0-500,0$ & 0,999 & $6,4 \pm 1,8$ & $21,4 \pm 6,1$ \\
Atrazina & $20,0-500,0$ & 0,999 & $0,9 \pm 0,1$ & $3,1 \pm 0,2$ \\
Carbaril & $20,0-500,0$ & 0,999 & $0,5 \pm 0,2$ & $1,5 \pm 0,6$ \\
Carbofurano & $20,0-500,0$ & 0,999 & $4,4 \pm 0,6$ & $14,8 \pm 1,9$ \\
Simazina & $20,0-500,0$ & 0,999 & $0,3 \pm 0,1$ & $1,1 \pm 0,1$ \\
Trifluralina & $20,0-500,0$ & 0,999 & $3,9 \pm 0,7$ & $12,9 \pm 2,2$ \\
\hline
\end{tabular}

Estudo de recuperação

Uma das maneiras de se determinar a exatidão do método analítico é aplicar a metodologia em amostras contendo quantidades co- nhecidas dos compostos de interesse ${ }^{38}$

Dessa forma, para avaliar a eficiência do processo de extração, a cada coleta realizada foram adicionadas concentrações conhecidas dos padrões (concentração final de $4 \mu \mathrm{g} \mathrm{L}^{-1}$ de cada composto) em uma amostra de água superficial, uma amostra de água tratada e uma amostra água ultrapura. Deste modo, obtiveram-se no final do programa 6 amostras de água superficial, 6 amostras de água tratada e 12 amostras de água ultrapura para o estudo de recuperação do método. Os resultados da recuperação estão apresentados na Tabela 4.

Embora os valores de desvio padrão relativos (DPR) obtidos não terem sido tão baixos quanto os obtidos por Lebre ${ }^{38}$, são menores que os $30 \%$ considerados pela $\mathrm{EPA}^{11}$. Também neste estudo o aldicarbe e a trifluralina foram os compostos que apresentaram as menores porcentagens de recuperação e os maiores valores de DPR.

Segundo Lebre ${ }^{38}$, a baixa recuperação da trifluralina está associada a sua alta massa molecular e baixa polaridade, possuindo forte afinidade pelo material extrator. O inverso ocorre com o aldicarbe que possui baixo peso molecular e solubilidade em água relativamente alta $\left(4,93 \mathrm{~g} \mathrm{~L}^{-1}\right)$. Lebre ${ }^{38}$, ainda, levanta a hipótese de que o aldicarbe quando associado ao ácido húmico, presente nas amostras de águas superficial e tratada, tenha sua solubilidade diminuída, aumentando sua carga e afinidade com o material extrator, melhorando a sua recuperação, como pode ser observado na Tabela 4. Balinova ${ }^{11}$ afirma que colunas de SPE empacotadas com $\mathrm{C}_{18}$ não são ideais para extração de compostos altamente polares como aldicarbe, metomil e dimetoato em amostras de água, pois as recuperações são muito baixas.

\section{Locais de amostragem e periodicidade de coleta}

A caracterização das variáveis físicas e químicas da água bruta e da água tratada pertencente à bacia hidrográfica do Ribeira de Iguape, principalmente quanto à presença dos agrotóxicos, foi realizada nas áreas de captação superficial e nas estações de tratamento de água operadas pela SABESP.

Estudos iniciais abordaram todos os 18 pontos de captação superficial e suas respectivas ETA's, sendo realizadas duas coletas. Após avaliação prévia, o estudo foi redirecionado, sendo avaliados em 10 sistemas, com adoção dos seguintes critérios para escolha das estações de coleta: 9 pontos com maior probabilidade de impacto agrícola e 1 ponto de amostragem em local totalmente preservado.

Foram realizadas 6 coletas, abordando períodos chuvoso e seco: março de 2002 (11/3 a 14/3); junho de 2002 (19/6 a 01/7); setembro de 2002 (10/9 a 16/9); novembro de 2002 (20/11 a 25/11); fevereiro de 2003 (13/2 A 20/2) e janeiro de 2004 (25/1 a 28/1). No total, 152 amostras foram coletadas, entre amostras de águas superficial e tratada.

Os 10 pontos de coleta monitorados, durante todo o período de trabalho, localizam-se nos municípios de Barra do Turvo, Cajatí,

Tabela 4. Estudo de recuperação dos compostos avaliados em amostras de água ultrapura, água superficial e água tratada

\begin{tabular}{|c|c|c|c|c|c|c|c|c|c|}
\hline \multirow[t]{2}{*}{ Compostos } & \multicolumn{3}{|c|}{ Água ultrapura } & \multicolumn{3}{|c|}{ Água superficial } & \multicolumn{3}{|c|}{ Água tratada } \\
\hline & Rec. $(\%)$ & DPR & $\mathrm{CV}(\%)$ & Rec. $(\%)$ & DPR & $\mathrm{CV}(\%)$ & Rec. $(\%)$ & DPR & $\mathrm{CV}(\%)$ \\
\hline Aldicarbe & 32 & 13 & 41 & 89 & 21 & 24 & 92 & 27 & 29 \\
\hline Simazima & 92 & 7 & 8 & 106 & 8 & 8 & 105 & 9 & 9 \\
\hline Carbofurano & 108 & 7 & 6 & 101 & 9 & 9 & 104 & 10 & 10 \\
\hline Carbaril & 105 & 7 & 7 & 108 & 6 & 5 & 105 & 8 & 8 \\
\hline Atrazina & 88 & 10 & 12 & 106 & 5 & 5 & 109 & 16 & 15 \\
\hline Trifluralina & 56 & 14 & 25 & 64 & 14 & 22 & 64 & 7 & 11 \\
\hline
\end{tabular}

$\mathrm{n}=6$ para as amostras de água superficial e tratada e 12 para amostras de água ultrapura; Rec = recuperação, DPR = desvio padrão relativo e $\mathrm{CV}=$ coeficiente de variação. 
Cananéia, Eldorado, Iguape, Iporanga, Juquitiba, Juquiá, Registro e Sete Barras.

\section{Coleta, preservação e análise das amostras de água}

As amostragens foram realizadas com auxílio da equipe de coletas da Unidade de Negócios da SABESP de Registro, de acordo com o Manual de coleta da Companhia de Tecnologia de Saneamento Ambiental, CETESB ${ }^{39}$.

Foram coletadas amostras de água superficial e água tratada, em vidros âmbar de $1 \mathrm{~L}$ contendo $30 \mathrm{~mL}$ de solução tampão $\mathrm{pH} 3 \mathrm{e} \cong 1,00$ $\mathrm{g}$ de tiossulfato de sódio ${ }^{40}$. As amostras, devidamente identificadas, foram mantidas sob refrigeração à temperatura de $4{ }^{\circ} \mathrm{C}$.

Nos laboratórios do Controle Sanitário da SABESP de Registro foram analisados os parâmetros físico-químicos de cor, turbidez e pH. Em seguida as amostras foram para os laboratórios do IPEN, onde foram filtradas em membranas de $0,45 \mu \mathrm{m}$, para a eliminação de partículas em suspensão. Separaram-se alíquotas de $250 \mathrm{~mL}$, mantidas em pH 3, para a determinação dos resíduos de agrotóxicos. Estas foram submetidas à extração em fase sólida - SPE, em colunas de polipropileno de $3 \mathrm{~mL}$ (preenchidaS com $500 \mathrm{mg}$ da fase $\mathrm{C}_{18}$ ).

Analisaram-se os agrotóxicos atrazina, simazina, trifluralina, aldicarbe, carbaril e carbofurano por cromatografia líquida de alta eficiência com detecção UV/vis ${ }^{2,26,38}$.

\section{RESULTADOS E DISCUSSÃO}

\section{Avaliação da temperatura e precipitação}

A água destinada ao abastecimento público na região é captada em três diferentes compartimentos: manancial superficial, manancial subterrâneo e manancial de serra. Neste trabalho foram estudados os pontos de captação superficial, portanto, com maior probabilidade de sofrer contaminações provenientes de atividades antrópicas e variações da intempérie.

No período de chuvas, geralmente, ocorre um aumento da concentração de matéria orgânica dissolvida e de material particulado que são carreados para os corpos d'água. A decomposição microbiana dessa matéria orgânica consome grande parte do oxigênio dissolvido, aumentando o grau de desoxigenação da água, com conseqüências danosas sobre o metabolismo do sistema aquático ${ }^{41}$. Em períodos de seca, normalmente são verificadas baixas concentrações de substâncias nos corpos d'água. Essa baixa concentração pode ser justificada pela ausência de escoamento superficial proveniente das águas de chuvas ${ }^{26}$.

A região situa-se no limite entre clima tropical e subtropical, ainda sob influência dos ventos do sudeste. Estes ventos sopram constantemente do sudeste rumo ao Equador, têm sua origem na forte queda de pressão atmosférica entre o centro de alta pressão (anticiclone) subtropical do Atlântico sul entre latitudes $20^{\circ}$ e $30^{\circ} \mathrm{e}$ o centro de baixa pressão (ciclone) equatorial. Típica dessa região costeira é a intensidade pluviométrica, além da distribuição diferenciada das chuvas ${ }^{42}$.

A região litorânea da UGRHI 11 (estação de Iguape) apresenta características climáticas com temperatura média anual de $21,5^{\circ}$ C, precipitação normal anual de cerca de $1.900 \mathrm{~mm}$ e unidade relativa do ar de aproximadamente $70 \%$. Chove em média cerca de $1.400 \mathrm{~mm} \mathrm{ano}^{-1}$, sendo que na sub-bacia de Juquiá com $1.500 \mathrm{~mm}$ $\mathrm{ano}^{-1}$ chove mais que na sub-bacia do Ribeira de Iguape, abrangendo as áreas de drenagens a jusante de Registro. O período mais chuvoso vai de setembro a março, sendo janeiro o mês de maior pluviosidade. Entre os meses de abril e agosto, período de seca, a precipitação média fica ao redor de $50 \mathrm{~mm}$, sendo o mês de agosto o menos chuvoso.

O clima da região não é homogêneo devido a fatores locais como a presença das serras, vegetação e proximidade do mar, principalmente, em relação à precipitação que apresenta um valor anual médio de $1,876 \mathrm{~mm}$ para os dados obtidos na estação meteorológica de Cananéia e 1,175 e 1,243 mm para as estações de Eldorado e Miracatu, respectivamente.

Durante o período de coleta, as estações meteorológicas de Jacupiranga e Cananéia (Centro Integrado e Informações agrometeorológicos - CIIAGRO ${ }^{43}$ ) registraram médias acima de $600 \mathrm{~mm}$ no mês de janeiro de 2003. Pode-se observar que a região de maneira geral, apresenta temperatura média de $23,2{ }^{\circ} \mathrm{C}$, que oscila entre 28 e $18{ }^{\circ} \mathrm{C}$, e precipitação anual média de $1,758 \mathrm{~mm}^{43}$.

Análise dos parâmetros físico-químicos das amostras de água superficial e tratada

Os gráficos representados nas Figuras 1, 2, e 3 foram construídos com os valores obtidos nas análises físico-químicas das amostras de água superficial e tratada, coletadas durante o monitoramento.

$\mathrm{Na}$ Figura 1 está representado o gráfico que relaciona o $\mathrm{pH}$ das amostras com as coletas, para as amostras de água superficial. Por meio dos gráficos observa-se que houve uma diminuição no $\mathrm{pH}$ das amostras dos períodos de chuva como fevereiro de 2003 e janeiro de 2004, principalmente nas amostras de água superficial, mas todas as mediadas estão na faixa de $\mathrm{pH}$ 6,0 - 9,0 como recomendado pela resolução CONAMA no $357 / 05$ para corpos de água de classe $2^{3}$ (Tabela 1). Após o tratamento, o pH das amostras manteve-se dentro da faixa permitida pela Portaria $n^{\circ} 518 / \mathrm{MS} / 04$, entre 6,0 - 9,5.

\section{VALORES REFERENTES AO PH DAS AMOSTRAS DE} ÁGUA SUPERFICIAL

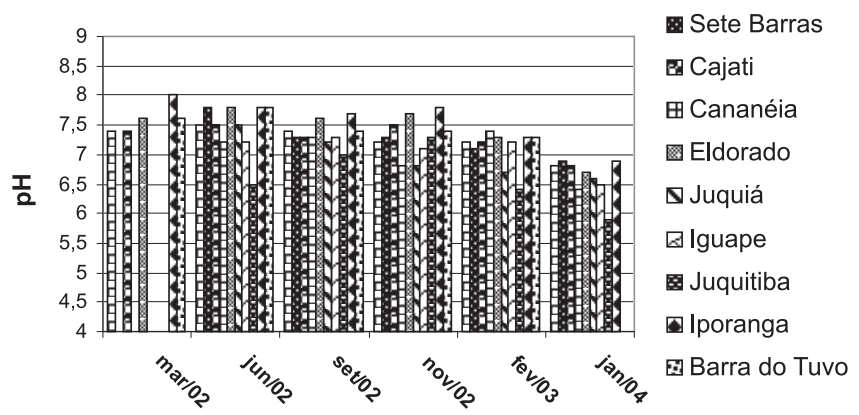

Figura 1. Variação temporal e espacial dos valores de pH das amostras de água superficial

Na Figura 2 está representado o gráfico que relaciona a cor das amostras com as datas de coletas, para as amostras de água superficial. Pode-se observar na Figura 2 que as amostras de água superficial, no período de cheia, apresentam valores maiores para cor na sua maioria bem acima de $75 \mathrm{UH}$ (unidade Hazen - mg Pt-Co L ${ }^{-1}$ ), limite máximo determinado pelo CONAMA n 357/05 para corpos d'água de classe $2^{3}$. Quanto à água tratada todos os valores obtidos foram $<5 \mathrm{UH}$, dentro da faixa permitida pela Portaria $n^{\circ} 518 / \mathrm{MS}$ / $04, \leq 15 \mathrm{UH}$.

Na Figura 3 estão representados os gráficos que relacionam a turbidez das amostras com as datas de coletas, para as amostras de água superficial. Conforme observado para o parâmetro cor, também se observa na Figura 3 que as amostras de água superficial, no período de chuva, apresentam valores maiores de turbidez. Após o tratamento da água, os valores para a turbidez ficaram abaixo de 1,0 UNT para todas as amostras monitoradas, exceto para amos- 


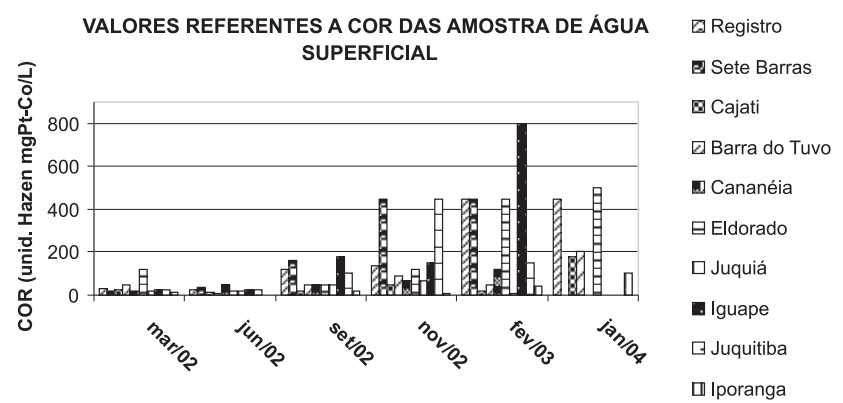

Figura 2. Variação temporal e espacial dos valores da cor das amostras de água superficial

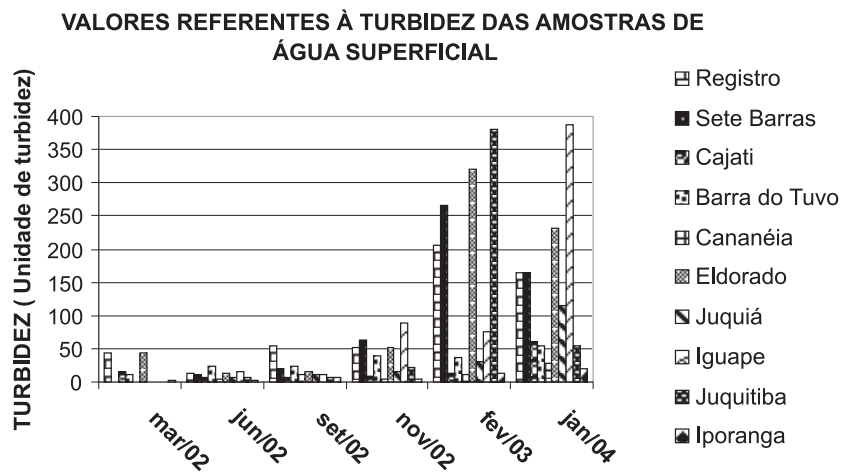

Figura 3. Variação temporal e espacial dos valores de turbidez das amostras de água superficial

tras de Cajatí em setembro de 2002 e Barra do Turvo em janeiro de 2004 que apresentaram valores iguais a 1,6 UNT.

\section{Análise dos resíduos de agrotóxicos em amostras de água superficial e tratada}

A bacia hidrográfica do Rio Ribeira de Iguape é um importante ecossistema para o desenvolvimento regional e estadual, no tocante à disponibilidade de recursos hídricos, contemplando o principal bioma do estado, a Mata Atlântica. Atualmente este sistema tem sido estudado sob vários aspectos, principalmente social e ambiental. Por ser considerada uma das maiores áreas com preservação de Mata Atlântica do estado, carente de área industrial e com intensa atividade agrícola o diagnóstico ambiental realizado forneceu uma fotografia atual do impacto agrícola na região. Foram estudadas áreas de captação destinadas ao abastecimento público pertencente à bacia hidrográfica do Ribeira de Iguape. Caracterizou-se e avaliou-se a qualidade da água da região e verificaram-se as inter-relações entre os aspectos básicos de metereologia, hidrologia e uso agrícola do solo.

Observou-se que das 76 amostras de água superficial analisadas, apenas uma amostra apresentou resíduo de aldicarbe, uma apresentou resíduo de simazina, 16 apresentaram resíduo de carbofurano, uma de atrazina e três apresentaram resíduo de trifluralina. O carbaril não foi detectado em nenhuma das 76 amostras analisadas.

Os resultados demonstraram que, apesar das concentrações encontradas serem extremamente baixas $\left(\mu \mathrm{g} \mathrm{L}^{-1}\right)$, a água tratada também apresentou resíduos de agrotóxicos, pois das 76 amostras analisadas 4 apresentaram resíduos de simazina, 7 de carbofurano, 1 de carabaril, 2 de atrazina e 1 de trifluralina. $O$ aldicarbe não foi detectado em nenhuma das 76 amostras analisadas.

O carbofurano foi encontrado em 23 amostras do total de 152 analisadas, entre água superficial e tratada, portanto, aproximadamente, $15 \%$ das amostras apresentaram resíduo de carbofurano.
Este resultado é coerente com o comportamento das atividades agrícolas da região, uma vez que o carbofurano está entre os princípios ativos mais vendidos e aplicados na área de estudo ${ }^{25}$.

Dos pontos de coleta estudados, as áreas de captação pertencentes aos municípios de Iguape, Juquitiba, Iporanga e Sete Barras foram os pontos que apresentaram os maiores números de amostras positivas (ou impactadas), sendo um total de 7, 6, 5 e 4 amostras respectivamente, das 12 amostras analisadas de cada ponto.

$\mathrm{O}$ ponto de captação da ETA de Iguape fica próximo à foz do rio Ribeira de Iguape (no mar), o que indica que neste ponto o rio recebe a contribuição de toda a bacia hidrográfica. $\mathrm{O}$ rio Ribeira de Iguape possui ao longo de quase toda margem cultura de banana, conforme observado nas cidades de Eldorado, Sete Barras e Registro durante as visitas a região.

Isso explica a maior freqüência de amostras contaminadas nas regiões de Iguape e Sete Barras ${ }^{25}$.

Juquitiba apresentou grande impacto relativo ao uso do solo pela agricultura. Essa influência se deve, principalmente, pela proximidade de unidades com alta atividade agrícola como Sorocaba, localizada na bacia do Médio e Alto Tietê, região de intensa atividade agrícola.

A captação da ETA de Iporanga é feita no rio Iporanga; embora sua nascente fique em Apiaí, o rio percorre grande parte dentro do Parque Estadual do Alto do Ribeira - PETAR, onde apesar de Área de Proteção Ambiental (APA) existem culturas de tomate e pêssego próximo à nascente ${ }^{22}$, o que provavelmente pode ter causado a grande incidência de amostras positivas.

Do total das 152 amostras analisadas: 76\% não apresentaram resíduos de agrotóxicos, $14 \%$ apresentaram resíduos de carbofurano, $3 \%$ de trifluralina, $2 \%$ de atrazina e $3 \%$ de simazina. As amostras provenientes das coletas de Iguape foram as que apresentaram maior incidência de resíduos de agrotóxicos, seguidas pelas amostras de Eldorado, Barra do Turvo e Iporanga. Estes resultados mostram que, embora as concentrações encontradas sejam extremamente baixas, da ordem de $\mu \mathrm{g} \mathrm{L}^{-1}$, não comprometendo a qualidade da água da Bacia para consumo humano, esta já apresenta indícios de contaminação pelo uso de agrotóxico na região, principalmente provenientes das plantações de banana.

$\mathrm{O}$ alto índice pluviométrico apresentou grande influência no carreamento dos agrotóxicos para os rios da Bacia, pois houve maior incidência de amostras positivas no período de cheia, como mostram os gráficos apresentados na Figura 4.

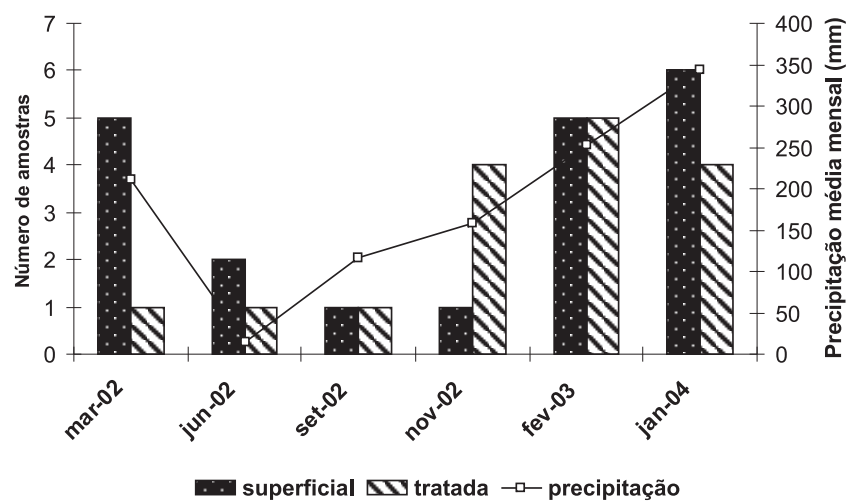

Figura 4. Gráfico comparativo de intensidade pluviométrica e número de amostras positivas para resíduos dos agrotóxicos estudados

Analisando-se os resultados das Figuras 2, 3 e 4 correlacionados aos indicativos de cor, turbidez, para água bruta, e número de amostras positivas para resíduos dos agrotóxicos, respectivamente, observa-se que estas medidas apresentaram um aumento nos seus 
valores no período de cheia. Este fenômeno deve estar correlacionado com o incremento do deflúvio superficial, ocorrido neste período, o qual está associado ao transporte de agrotóxicos (aplicados na lavoura) e ao material particulado, influenciando na cor, pela presença de substâncias solúveis, e na turbidez.

O desenvolvimento do trabalho permitiu concluir que o monitoramento da qualidade da água deve ser direcionado a problemas específicos, principalmente levando-se em conta problemas regionais, o uso e ocupação do solo. Os estudos mostraram a dependência da composição da água com as características do ecossistema adjacente.

\section{CONCLUSÕES}

A agricultura é um dos principais fatores mais impactantes quando o tema é qualidade da água, mesmo em áreas consideradas ambientalmente preservadas. Vários fatores devem ser considerados, como as características geológicas da região, o uso e ocupação do solo, sendo de primordial importância o tipo de atividade humana desenvolvida. As características gerais da qualidade da água natural são muito variáveis e derivam dos ambientes por onde circulam ou são armazenadas.

Quanto ao diagnóstico realizado para verificar a contaminação causada pelo uso de agrotóxicos nos corpos d'água, pode-se concluir que a escolha dos agrotóxicos para estudo do monitoramento deve levar em conta fatores primordiais, entre eles: índice de aplicação na região; pertencerem ao grupo de agrotóxicos contemplados pela OMS e FAO; a persistência destes compostos no meio ambiente (os carbamatos - aldicarbe, carbaril, carbofurano - são inseticidas com persistência no meio ambiente de 1 a 18 meses) e alguns destes, recentemente, inclusos no controle de potabilidade, como a atrazina, a simazina (grupo das triazinas) a trifluralina (grupo das nitroanilinas) estão entre os herbicidas mais utilizados no mundo.

Verificou-se que a qualidade da água é influenciada pela sazonalidade. Em períodos de chuva, detectou-se uma concentração maior de agrotóxicos na água superficial provocada pela lixiviação do solo pela chuva. Observou-se que as amostra de água superficial apresentaram uma maior incidência de resíduos de carbofurano, fato previsto e comprovado devido à grande mobilidade em meio aquoso. As amostras positivas, isto é, onde foram detectados resíduos de agrotóxicos, apresentaram maior frequiência de observações durante os períodos de chuva, principalmente, quando os índices pluviométricos ultrapassam os $300 \mathrm{~mm}$ na média mensal. Uns dos principais fatores contribuintes foram as enchentes, que ocorrem com grande frequiência neste período. Embora as concentrações observadas dos resíduos de agrotóxicos fossem baixas, os resultados mostraram indícios de contaminação e do impacto da agricultura nos corpos d'águas da bacia hidrográfica do Rio Ribeira de Iguape.

Ações de controle de uso e preservação das áreas de captação devem ser observadas. A primeira linha de defesa é proteger a água da contaminação. O melhor método é proteger a fonte, procedimento preferível ao tratamento da água contaminada de forma a tornar-se apta para consumo humano.

Avaliando-se as características físico-químicas da água superficial e tratada pode-se verificar a eficiência dos processos de tratamento aplicados nas ETA's da Unidade de Negócio do Vale do Ribeira da SABESP. Os parâmetros estudados ( $\mathrm{pH}$, cor e turbidez) apresentaram homogeneidade para os valores obtidos na análise da água tratada, além de estarem dentro das faixas indicadas pela legislação de potabilidade vigente. A turbidez da água está associada ao material particulado em suspensão, portanto o tratamento e controle deste parâmetro devem auxiliar no controle dos agrotóxicos estudados que apresentaram potencial alto de transporte associado ao sedimento.

A avaliação ambiental da bacia torna-se um importante instrumento que poderá contribuir não só para a avaliação da qualidade da água e o entendimento da dinâmica do sistema, mas também para a escolha de medidas de manejo e recuperação deste ecossistema.

Um dos grandes desafios na área de políticas públicas é harmonizar o desenvolvimento econômico/industrial com a preservação do meio ambiente, de forma que a exploração destes recursos não acarrete maiores danos aos ambientes e ao homem. Dessa forma, os recursos hídricos, principalmente os recursos hídricos destinados ao abastecimento público, devem ser integrados a um planejamento regional dentro do contexto holístico, unindo o conhecimento científico e a ação do poder público para sua utilização e manutenção.

\section{MATERIAL SUPLEMENTAR}

Na Tabela 1S são apresentados os usos autorizados no Brasil e as classificações toxicológicas dos agrotóxicos estudados neste trabalho.

$\mathrm{Na}$ Tabela $2 \mathrm{~S}$ é apresentada uma descrição dos pontos ou estações de coleta agrupadas por município.

Os resultados das análises de resíduos de agrotóxicos nas amostras de água superficial e tratada, utilizando o método SPE - LC UV/visível são apresentados de forma resumida nas Tabelas 3S e 4S.

Esse material está disponível gratuitamente em http:// quimicanova.sbq.org.br, na forma de arquivo PDF.

\section{AGRADECIMENTOS}

Fapesp Políticas Públicas 00/02024-4; 03/06419-1, Capes, Sabesp.

\section{REFERÊNCIAS}

1. Pires, M. A. F.; Cotrim, M. E. B.; Marques, M. N.;Bohere-Morel, M. B. C.; Martins, E. A. J.; Revista Brasileira de Pesquisa e Desenvolvimento. 2001, 3, 127.

2. Pires, M. A. F.; Marques, M. N.; Cotrim, M. E. B.; Anais do II Congresso Brasileiro de Pesquisas Ambientais e Saúde, Santos, Brasil, 2002, em CDROM.

3. BRASIL. Ministério do Desenvolvimento Urbano e Meio Ambiente. Conselho Nacional do Meio Ambiente (CONAMA); Resolução do $n^{\circ} 357$, de 17/03/05, Brasília: Brasil.

4. Piveli, R. P.; Kato, M. T.; Qualidade das águas e poluição: Aspectos FísicoQuímicos, $1^{\text {a }}$ ed., ABES-Associação Brasileira de Engenharia Sanitária e Ambiental, São Paulo, 2006, cap. 6 e 7.

5. Merten, G. H.; Minella, J. P.; Agroecol. e Desenvol. Rur. Sustent. 2002, 3, 33.

6. http://www.who.int/water_sanitation_health/en, acessada em Junho 2006.

7. http://www.mma.gov.br/, acessada em Dezembro 2003.

8. Hayes, W. J.; Laws, E. R.; Handbook of Pesticides Toxicology, $1^{\text {st }}$ ed., Academic Press: San Diego, 1997.

9. Barceló, D.; Veronique, B.; Durand, G.; J. Cromatogr. 1992, 607, 319.

10. Barceló, D.; J. Cromatogr. 1993, 643, 117.

11. Barceló, D.; Environmental analysis techniques, applications and quality assurance, $1^{\text {st }}$ ed., Elsevier Sciense Plublishers: Amsterdam, 1993.

12. Biziuk, M.; Przyjany, A.; Czerwinski, J.; Wiergowski, M.; J. Chromatogr., A 1996, 754, 103.

13. Balinova, A.; J. Chromatogr., A 1996, 754, 125.

14. Albanis, T. A.; Hela, D. G.; Sakellarides, T. M.; Konstantinou, I. K.; J. Chromatogr., A 1998, 823, 59.

15. Azevedo, D. A.; Lacorte, S.; Vinhas, T.; Viana, P.; Barceló, D.; J. Chromatogr., A 2000, 879, 13.

16. Hostetler, K. A.; Thurman, E. M.; The Science of the Total Environment 2000, 248, 147.

17. Sabik, H.; Jeannot, R.; Rondeau, B.; J. Chromatogr., A 2000, 885, 217.

18. Dijkman, E.; Mooibroek, D.; Hoogerbrugge, R.; Hogendoorn, E.; Sancho, J. V.; Pozo, O.; Hernández, F.; J. Chromatogr., A 2001, 926, 113. 
19. Hernández, F.; Sancho, J. V.; Pozo, O.; Lara, A.; Pitarch, E.; J. Chromatogr., A 2001, 939, 1.

20. Quintana, J.; Marti, I.; Ventura, F.; J. Chromatogr., A 2000, 938, 3.

21. Bossi, R.; Vejrup, K. V.; Mogensen, B. B.; Asmn, W. A. H.; J. Chromatogr., A 2002, 957, 27.

22. Molander, S.; Moraes, R.; Technical Environmental Planning CTH, Report, 1998.

23. Katsuóka, L.; Pires, M. A. F.; Vaz, J. M.; Cotrim, M. E. B.; Resumos do VI Encontro de Ecotoxicologia, São Carlos, Brasil, 2000.

24. Marques, M. N.; Cotrin, M. E. B.; Pires, M. A. F.; Anais do XI World Water Congress - Water Resources Management in the $21^{\text {st }}$ Century, Madrid, Espanha, 2003, CD-ROM.

25. Marques, M. N.; Tese de Doutorado, Instituto de Pesquisas Energéticas e Nucleares, Brasil, 2005.

26. Katsuóka, L.; Tese de Doutorado, Instituto de Pesquisas Energéticas e Nucleares, Brasil, 2001.

27. Dean, J. R.; Wade, G.; Barnadas, I.; J. Chromatogr., A 1996, 733, 295.

28. Veiga, M. M.; Silva, D. M.; Veiga, L. B. E; Faria, M. V. C.; Cad. Saúde Pública 2006, 22, 2391

29. van der Hoff, G. R.; van Zoonen, P. T.; J. Chromatogr., A 1999, 843, 301.

30. Stackelberg, P. E.; Kauffman, L. J.; Ayers, M. A.; Baeh, A. L.; Environ. Toxicol. Chem. 2001, 20, 853.

31. Larini, L.; Toxicologia dos Praguicidas, $1^{\text {a }}$ ed., Ed. Manole: SP, 1999.
32. http://www.anvisa.gov.br/toxicologia/monografias/index.htm, acessada em Dezembro 2006.

33. http://toxnet.nlm.nih.gov/, acessada em Dezembro 2006.

34. http://www.cetesb.sp.gov.br/Agua, acessada em Dezembro 2006.

35. CETEC; Relatório de Situação dos Recursos Hídricos da Bacia do Ribeira de Iguape e Litoral Sul, UGRHI-11 - Relatório Zero, publicação: 20/11/ $00 \mathrm{em}$ http://www.sigrh.sp.gov.br, acessada em Abril 2004.

36. DAEE - Departamento de Águas e Energia Elétrica; Disponibilidade da água na bacia do Ribeira, Relatório 2000.

37. BRASIL. Ministério da Saúde; Portaria $n^{0} 518$ de 25/3/2004, em http:// www.funasa.gov.br, acessada em Dezembro 2006.

38. Lebre, D. T. Dissertação de Mestrado, Instituto de Pesquisas Energéticas e Nucleares, Brasil, 2000.

39. CETESB - Companhia de Tecnologia de Saneamento Ambiental; Guia de coleta de amostra, 1985.

40. Standard Methods for the Examination of Water and Waste Water, $19^{\text {th }}$ ed. New York: NY, 1997, Carbamate pesticide (6610)/HPLC Method. P. 6-109 a 6-114.

41. Esteves, F. A.; Fundamentos de Limnologia, Ed. Interciência, FINEP: Rio de Janeiro, 1988.

42. SÃO PAULO. Secretaria do Meio Ambiente (SMA)/Secretaria da Educação; Programa de Educação Ambiental do Vale do Ribeira, 1992.

43. http://ciiagro.iac.br, acessada em Dezembro 2006. 


\section{AVALIAÇÃO DO IMPACTO DA AGRICULTURA EM ÁREAS DE PROTEÇÃO AMBIENTAL, PERTENCENTES À BACIA HIDROGRÁFICA DO RIO RIBEIRA DE IGUAPE, SÃO PAULO}

\section{Maria Nogueira Marques*, Marycel Barbosa Cotrim e Maria Aparecida Faustino Pires}

Centro de Química e Meio Ambiente, Instituto de Pesquisas Energéticas e Nucleares, Av. Prof. Lineu Prestes, 2242, 05508-000

São Paulo - SP, Brasil

Osvaldo Beltrame Filho

Unidade de Negócios do Vale do Ribeira, Companhia de Saneamento Básico do Estado de São Paulo, Registro - SP, Brasil

Tabela 1S. Agrotóxicos: Usos autorizados no Brasil e as classificações quanto à toxidade ${ }^{31-33}$.

\begin{tabular}{|c|c|c|}
\hline Agrotóxicos & Usos autorizados no Brasil & Toxicologia \\
\hline Aldicarbe & $\begin{array}{l}\text { Aplicado no solo das culturas de: algodão, } \\
\text { batata, café, citros, feijão } \\
\text { e no pseudocaule da banana. }\end{array}$ & $\begin{array}{l}\text { Classe Ia; segundo a IARC é classificado como um agrotóxico } \\
\text { do Grupo } 3 \text { - não classificado como carcinogênico. } \\
\text { VMP (Valor Máximo Permissível)-(EPA): } 10 \mu \mathrm{g}^{-1} \text { e não } \\
\text { consta como parâmetro de controle na Portaria } \mathrm{n}^{\circ} 518 / \mathrm{MS} / 04 \text {. }\end{array}$ \\
\hline Atrazina & $\begin{array}{l}\text { Aplicação em pré e pós-emergência das } \\
\text { plantas infestantes nas culturas de abacaxi, } \\
\text { cana-de-açúcar, milho, pinus, seringueira, } \\
\text { sisal e sorgo. }\end{array}$ & $\begin{array}{l}\text { Classe III; segundo a IARC é classificado como um agrotóxico } \\
\text { do Grupo } 2 \mathrm{~B} \text { - possível carcinogênico ao Homem. } \\
\text { VMP (Valor Máximo Permissível): } 3 \mu \mathrm{g} \mathrm{L}^{-1} \text { (EPA) e } \\
\left.2 \mu \mathrm{g} \mathrm{L} \mathrm{L}^{-1} \text { (Portaria } \mathrm{n}^{\circ} 518 / \mathrm{MS} / 04\right) \text {. }\end{array}$ \\
\hline Carbaril & $\begin{array}{l}\text { Aplicação foliar nas culturas de abacaxi, } \\
\text { abóbora, alho, banana, batata, cebola, } \\
\text { couve-flor, feijão, maçã, pastagens, } \\
\text { pepino, repolho e tomate. }\end{array}$ & $\begin{array}{l}\text { Classe II; segundo a IARC é classificado como um agrotóxico } \\
\text { do Grupo } 3 \text { - não classificado como carcinogênico. } \\
\text { VMP (Valor Máximo Permissível)-(EPA): } 10 \mu \mathrm{g} \mathrm{L}^{-1} \text { e não } \\
\text { consta como parâmetro de controle na Portaria } \text { no }^{\circ} 518 / \mathrm{MS} / 04 \text {. }\end{array}$ \\
\hline Carbofurano & $\begin{array}{l}\text { Aplicação no solo nas culturas de algodão, } \\
\text { amendoim, arroz, banana, batata, café, } \\
\text { cana-de-açúcar, cenoura, feijão, fumo, milho, } \\
\text { repolho, tomate e trigo. Aplicação em } \\
\text { sementes de algodão, arroz, feijão, milho e trigo. }\end{array}$ & $\begin{array}{l}\text { Classe Ib. } \\
\text { VMP (Valor Máximo Permissível)-(EPA): } 40 \mu \mathrm{g} \mathrm{L}^{-1} \mathrm{e} \\
\text { não consta na Portaria }{ }^{\circ} 518 / \mathrm{MS} / 04 \text {. }\end{array}$ \\
\hline Simazina & $\begin{array}{l}\text { Aplicação em pré e pós-emergência das } \\
\text { plantas infestantes nas culturas de abacaxi, } \\
\text { banana, cacau, café, cana-de-açúcar, citros, } \\
\text { maçã, milho, pinus, seringueira, } \\
\text { sisal, sorgo e uva. }\end{array}$ & $\begin{array}{l}\text { Classe III; segundo a IARC é classificado como um } \\
\text { agrotóxico do Grupo } 3 \text { - não classificado como carcinogênico. } \\
\text { O fígado constitui o órgão alvo na ação tóxica da } \\
\text { simazina, durante as exposições prolongadas. } \\
\text { VMP (Valor Máximo Permissível): } 4 \mu \mathrm{g} \mathrm{L}^{-1} \\
\text { (EPA) e } 2 \mu \mathrm{g} \mathrm{L}^{-1} \text { (Portaria }{ }^{\circ} 518 / \mathrm{MS} / 04 \text { ). }\end{array}$ \\
\hline Trifluralina & $\begin{array}{l}\text { Aplicação em pré-emergência das plantas } \\
\text { infestantes nas culturas de algodão, alho, } \\
\text { amendoim, arroz, berinjela, cana-de-açúcar, } \\
\text { cebola, cenoura, citros, couve, couve-flor, } \\
\text { eucalipto, feijão, feijão-vagem, girassol, } \\
\text { gladíolo, mamona, milho, pimentão, pinus, } \\
\text { quiabo, repolho, seringueira, rosa, soja e tomate. }\end{array}$ & $\begin{array}{l}\text { Classe III; segundo a IARC é classificado como um agrotóxico } \\
\text { do Grupo } 3 \text { - não classificado como carcinogênico. } \\
\text { VMP (Valor Máximo Permissível): } 2 \mu \mathrm{g} \mathrm{L}^{-1} \\
\text { (EPA) e } 20 \mu \mathrm{g} \mathrm{L}^{-1} \text { (Portaria n } \mathrm{n}^{\circ} 518 / \mathrm{MS} / 04 \text { ). }\end{array}$ \\
\hline
\end{tabular}

Classes: Ia - Extremamente tóxicos, Ib - Extremamente tóxicos, II - Altamente tóxicos, III - Mediamente tóxicos, IV - Pouco tóxicos. 
Tabela 2S. Descrição e agrupamento dos locais de coleta nas diferentes áreas de captação de água superficial e respectivas ETA’s

\begin{tabular}{|c|c|c|}
\hline Município & Local de Captação & Coordenadas Geodésicas dos pontos de coleta \\
\hline Registro & Rio Ribeira do Iguape & Captação S: $24^{\circ} 28^{\prime} 25^{\prime \prime}$ WO: $47^{\circ} 50^{`} 37^{\prime \prime}$ ETA S: $24^{\circ} 29^{\circ} 04^{\prime \prime}$ WO: $47^{\circ} 51^{`} 01^{\prime \prime}$ \\
\hline Sete Barras & Ribeira do Iguape & Captação S: $24^{\circ} 23^{\prime} 33^{\prime \prime}$ WO: $47^{\circ} 55^{\circ} 43^{\prime \prime}$ ETA S: $24^{\circ} 23^{\circ} 31^{\prime \prime}$ WO: $47^{\circ} 55^{\prime} 44^{\prime \prime}$ \\
\hline Cajati & Rio Jacupiranguinha & Captação S: $24^{\circ} 43^{\prime} 50^{\prime \prime}$ WO: $48^{\circ} 07^{\prime} 56^{\prime \prime}$ ETA S: $24^{\circ} 43^{`} 42^{\prime \prime}$ WO: $48^{\circ} 08^{`} 02^{\prime \prime}$ \\
\hline Cananéia & Rio Itapitangui & Captação S: $24^{\circ} 55^{`} 58^{\prime \prime}$ WO: $47^{\circ} 57^{`} 41^{\prime \prime}$ ETA S: $24^{\circ} 55^{`} 58^{\prime \prime}$ WO: $47^{\circ} 57^{`} 41^{\prime \prime}$ \\
\hline Eldorado & Rio Ribeira do Iguape & Captação S: $24^{\circ} 31^{\prime} 09^{\prime \prime}$ WO: $48^{\circ} 06^{\prime} 54^{\prime \prime}$ ETA S: $24^{\circ} 31^{\prime} 13^{\prime \prime}$ WO: $48^{\circ} 06^{\prime} 53^{\prime \prime}$ \\
\hline Juquiá & Rio Juquiá & Captação S: $24^{\circ} 19^{`} 12^{\prime \prime}$ WO: $47^{\circ} 37^{`} 30^{\prime \prime}$ ETA S: $24^{\circ} 18^{`} 48^{\prime \prime}$ WO: $47^{\circ} 38^{`} 27^{\prime \prime}$ \\
\hline Iguape & Rio Ribeira do Iguape & Captação S: $24^{\circ} 40^{\prime} 54^{\prime \prime}$ WO: $47^{\circ} 35^{\prime} 50^{\prime \prime}$ ETA S: $24^{\circ} 42^{\prime} 29^{\prime \prime}$ WO: $47^{\circ} 34^{\prime} 02^{\prime \prime}$ \\
\hline Juquitiba & Córrego dos Godinhos & Captação S: $23^{\circ} 56^{`} 00^{\prime \prime}$ WO: $47^{\circ} 03^{`} 38^{\prime \prime}$ ETA S: $23^{\circ} 55^{\prime} 51^{\prime \prime}$ WO: $47^{\circ} 03^{‘} 55^{\prime \prime}$ \\
\hline Iporanga & Rio Iporanga & Captação S: $24^{\circ} 34^{\circ} 49^{\prime \prime}$ WO: $48^{\circ} 35^{\circ} 25^{\prime \prime}$ ETA S: $24^{\circ} 35^{\circ} 06^{\prime \prime}$ WO: $48^{\circ} 35^{\circ} 46^{\prime \prime}$ \\
\hline Barra do Turvo & Rio Turvo & Captação S: $23^{\circ} 53^{`} 48^{\prime \prime}$ WO: $47^{\circ} 30^{`} 44^{\prime \prime}$ ETA S: $23^{\circ} 53^{\prime} 55^{\prime \prime}$ WO: $47^{\circ} 31^{\prime} 29^{\prime \prime}$ \\
\hline
\end{tabular}

Todos corpos d‘água são de classe 2, segundo a resolução CONAMA n 357/2005³.

Tabela 3S. Ocorrência de resíduos de agrotóxicos em $\mu \mathrm{g} \mathrm{L}^{-1}$ nas amostras de água superficial da Bacia Hidrográfica do rio Ribeira de Iguape, durante o período de março/2002 a fevereiro/2003 e em janeiro/2004

\begin{tabular}{|c|c|c|c|c|c|c|c|c|c|c|c|}
\hline \multirow[t]{2}{*}{ Localidade } & \multirow[t]{2}{*}{$\mathrm{n}$} & \multicolumn{2}{|c|}{ Aldicarbe } & \multicolumn{2}{|c|}{ Simazina } & \multicolumn{2}{|c|}{ Carbofurano } & \multicolumn{2}{|c|}{ Atrazina } & \multicolumn{2}{|c|}{ Trifluralina } \\
\hline & & Min - máx & Fq. & min - máx & Fq. & min - máx & Fq. & min - máx & Fq. & min - máx & Fq. \\
\hline Registro & 6 & $<0,17$ & n.d. & $<0,01$ & n.d. & $<0,12-0,32$ & 1 & $<0,02$ & n.d. & $<0,10$ & n.d. \\
\hline Sete Barras & 6 & $<0,17$ & n.d. & $<0,01$ & n.d. & $<0,12-0,24$ & 2. & $<0,02$ & n.d. & $<0,10$ & n.d. \\
\hline Cajati & 6 & $<0,17$ & n.d. & $<0,01$ & n.d. & $<0,12$ & n.d. & $<0,02$ & n.d. & $<0,10$ & n.d. \\
\hline Cananéia & 6 & $<0,17$ & n.d. & $<0,01$ & n.d. & $<0,12-0,52$ & 2 & $<0,02$ & n.d. & $<0,10-1,73$ & 1 \\
\hline Eldorado & 6 & $<0,17$ & n.d. & $<0,01$ & n.d. & $<0,12-0,56$ & 3 & $<0,02$ & n.d. & $<0,10$ & n.d. \\
\hline Pariquera Açu & 2 & $<0,17$ & n.d. & $<0,01$ & n.d. & $<0,10-0,15$ & 1 & $<0,02$ & n.d. & $<0,10-0,97$ & 1 \\
\hline Juquiá & 6 & $<0,17-2,15$ & 1 & $<0,01$ & n.d. & $<0,12$ & n.d. & $<0,02-0,06$ & 1 & $<0,10$ & n.d. \\
\hline Iguape & 6 & $<0,17$ & n.d. & $<0,01$ & n.d. & $<0,12-0,50$ & 3 & $<0,02$ & n.d. & $<0,10$ & n.d. \\
\hline Juquitiba & 6 & $<0,17$ & n.d. & $<0,01-0,03$ & 1 & $<0,12-0,31$ & 1 & $<0,02$ & n.d. & $<0,10-0,59$ & 1 \\
\hline Iporanga & 6 & $<0,17$ & n.d. & $<0,01$ & n.d. & $<0,12-0,11$ & 2 & $<0,02$ & n.d. & $<0,10$ & n.d. \\
\hline
\end{tabular}

$\mathrm{n}$ = número de amostras; Fq. = frequiência. Não foram detectados resíduos de agrotóxicos nas amostras de água bruta dos pontos de captação de: Jacupiranga, Barra do Turvo, Miracatu, Itariri, Pedro de Toledo, S. Lourenço da Serra, Paiol do Meio e Tapirai.

Tabela 4S. Ocorrência de resíduos de agrotóxicos em $\mu \mathrm{g} \mathrm{L}^{-1}$ nas amostras de água tratada da Bacia Hidrográfica do rio Ribeira de Iguape, durante o período de março/2002 a fevereiro/2003 e em janeiro/2004

\begin{tabular}{|c|c|c|c|c|c|c|c|c|c|c|c|}
\hline \multirow[t]{2}{*}{ Localidade } & \multirow[t]{2}{*}{$\mathrm{n}$} & \multicolumn{2}{|c|}{ Simazina } & \multicolumn{2}{|c|}{ Carbofurano } & \multicolumn{2}{|c|}{ Carbaril } & \multicolumn{2}{|c|}{ Atrazina } & \multicolumn{2}{|c|}{ Trifluralina } \\
\hline & & min - máx & $\mathrm{Fq}$. & min - máx & $\mathrm{Fq}$. & min - máx & Fq. & min - máx & Fq. & min - máx & $\mathrm{Fq}$. \\
\hline Sete Barras & 6 & $<0,01-0,26$ & 2 & $<0,12$ & n.d. & $<0,01-0,92$ & 1 & $<0,02$ & n.d. & $<0,10$ & n.d. \\
\hline Cajatí & 6 & $<0,01$ & n.d. & $<0,12-0,11$ & 2 & $<0,01$ & n.d. & $<0,02$ & n.d. & $<0,10$ & n.d. \\
\hline Cananéia & 6 & $<0,01$ & n.d. & $<0,12-2,24$ & 1 & $<0,01$ & n.d. & $<0,02$ & n.d. & $<0,10$ & n.d. \\
\hline Iguape & 6 & $<0,01-0,02$ & 1 & $<0,12-0,66$ & 1 & $<0,01$ & n.d. & $<0,02-0.22$ & 2 & $<0,10$ & n.d. \\
\hline Juquitiba & 6 & $<0,01-0,03$ & 1 & $<0,12-0,65$ & 1 & $<0,01$ & n.d. & $<0,02$ & n.d. & $<0,10-2,06$ & 1 \\
\hline Iporanga & 6 & $<0,01$ & n.d. & $<0,12-0,23$ & 2 & $<0,01$ & n.d. & $<0,02$ & n.d. & $<0,10$ & n.d. \\
\hline
\end{tabular}

$\mathrm{n}$ = número de amostras; Fq. = freqüência. Não foram detectados resíduos de agrotóxicos nas amostras de água tratada das ETAs de: Registro, Jacupiranga, Barra do Turvo, Eldorado, Pariquera Açu, Juquiá, Miracatu, Itariri, Pedro de Toledo, S. Lourenço da Serra, Paiol do Meio e Tapirai.

OBS: O método utilizado SPE-LC-UV/Visível é mais sensível que a técnica LC-UV/Visível, pois as amostras foram pré-concentradas 125 vezes, conforme descrito na metodologia. 